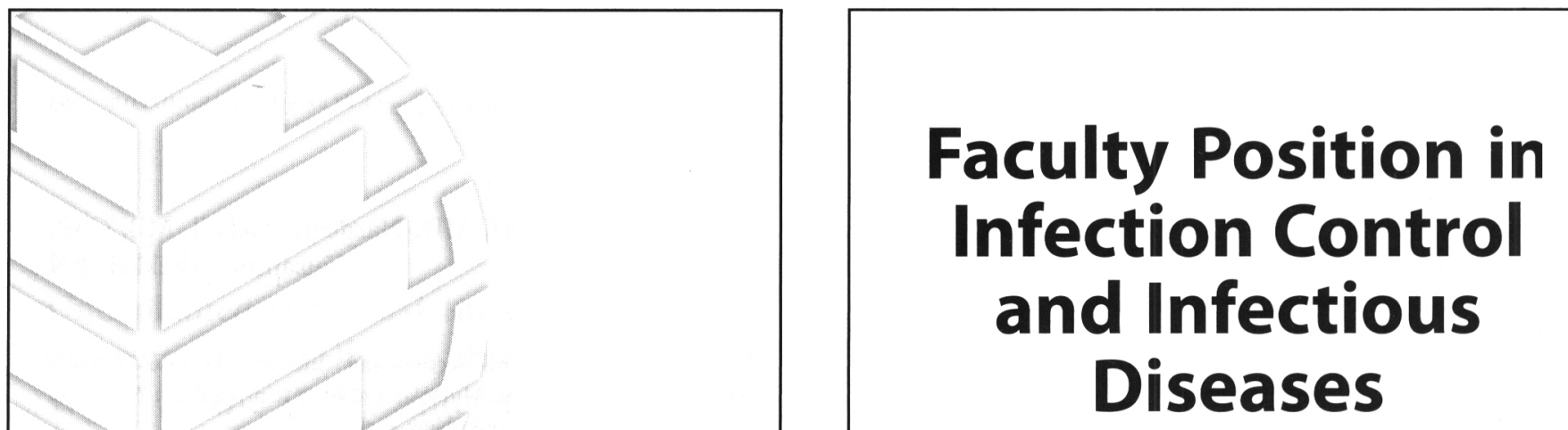

Connecting the work you love

with the lifestyle you deserve.

\title{
Hospital Epidemiologist
}

Carolinas HealthCare System is the third largest public healthcare system in the United States. With renowned facilities across North and South Carolina, we offer a unique environment where patients and physicians define success as a partnership of trust and reciprocity.

Carolinas Medical Center, the flagship facility of Carolinas HealthCare System, is distinguished throughout the Southeast by a reputation for excellence. Located in Charlotte, Carolinas Medical Center is an 843-bed teaching facility with one of the largest free-standing residency programs and a Level 1 Trauma Center.

The Department of Internal Medicine at Carolinas Medical Center is seeking an Epidemiologist who is board eligible/ board certified in ID and has at least 3.5 years of experience in infection control. This position is split, with $70 \%$ commitment to infection control activities and $30 \%$ to a combination of rounding on teaching ID consult service and clinics. We will rely on this person to direct and advise hospital infection control programs and activities. The position has an academic rank through the University of North Carolina - Chapel Hill that is commensurate with experience.

The wealth of opportunity you desire. The exceptional quality of life you deserve. Make your connection at Carolinas. To learn more about our opportunities, contact ryan.knox@carolinashealthcare.org or amy.jacobsen@ carolinashealthcare.org, or call (800) 847-5084. $\mathrm{EOE} / \mathrm{AA}$

Carolinas HealthCare System

Uncompromising Excellence. Commitment to Care.

The Infection Control Unit and the Division of Infectious Diseases at the Massachusetts General Hospital (Boston, MA) are recruiting for a physician at the Assistant or Associate Professor level in Healthcare Epidemiology and Infection Control to begin the fall of 2010. The successful candidate would serve as Associate Chief of the Infection Control Unit and Director of the Antimicrobial Stewardship Program and would participate in and develop research in Healthcare Epidemiology in collaboration with physician-scientists in the Clinical Microbiology Laboratory and Division of Infectious Diseases. The successful candidate would also direct the teaching of fellows in Healthcare Epidemiology and antimicrobial use and participate in the inpatient clinical consultation service in an exciting academic environment. The areas of focus would be reduction of antimicrobial resistant pathogens and management of antimicrobial use. Board Certification in Internal Medicine and Infectious Diseases is required. Interested candidates should forward a $\mathrm{CV}$, names of three references, and a one-page statement of career interests by May 31, 2010 to David C. Hooper, M.D., Chair, Search Committee, Division of Infectious Diseases, Massachusetts General Hospital, 55 Fruit Street, Boston, MA 02114.

Women and minority applicants are particularly encouraged to apply. 


\section{ADVERTISING 2010}

\section{Clinical Infectious Diseases and The Journal of Infectious Diseases}

\section{Advertising Rates:}

$\begin{array}{lll}\text { Full Page } & 73 / 4 " \times 103 / 8 " & \$ 730^{*} \\ \text { Vert Half } & 31 / 2 " \times 103 / 8 " & \$ 560^{*} \\ \text { Hori Half } & 73 / 4 " \times 53 / 16 " & \$ 560^{*} \\ \text { Trim Size } & 81 / 4 " \times 107 / 8 " & \\ \text { "denotes net rate, noncommissionable. } & \end{array}$

Rates apply to Recruitment Advertising only. Additional $\$ 50$ to typeset/design half page ad; $\$ 100$ for full page ad.

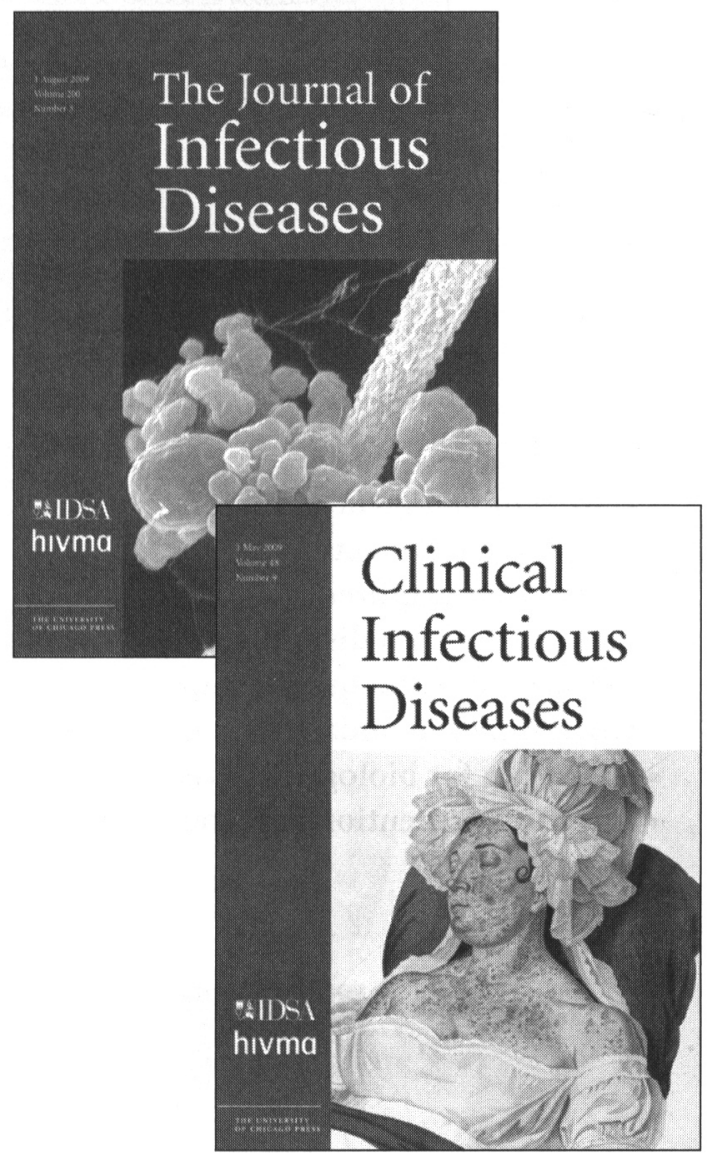

\section{Advertising Deadlines:}

Issue

January 1

Space \& Art

January 15

February 1

February 15

March 1

March 15

April 1

April 15

May 1

May 15

June 1

June 15

July 1

July 15

August 1

August 15

September 1

September 15

October 1

October 15

November 1

November 15

December 1

December 15

November 25

December 11

December 29

January 11

January 26

February 7

February 25

March 9

March 30

April 12

April 26

May 10

May 27

June 8

June 23

July 7

July 28

August 11

August 25

September 3

September 24

October 11

October 28

November 9

For recruitment as well as commercial advertising information please email DeLisa New at dnew@press.uchicago.edu; phone 773.702.5851; fax 773.702.0172. 


\section{The difference between a career and a purpose is about 8,000 miles.}




\section{Available March 2010}

\section{Practical Healthcare}

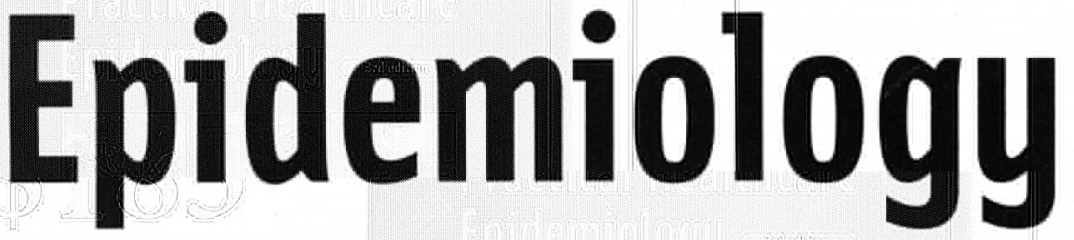

\section{3rd edition}

\section{Newly revised \& updated}

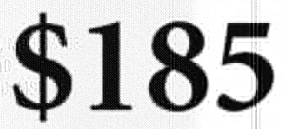

\section{Order your copy online at www.press.uchicago.edu}

\section{Address infection prevention and quality of} patient care with this newly updated, practical, hands-on guide to epidemiologic principles and prevention strategies.
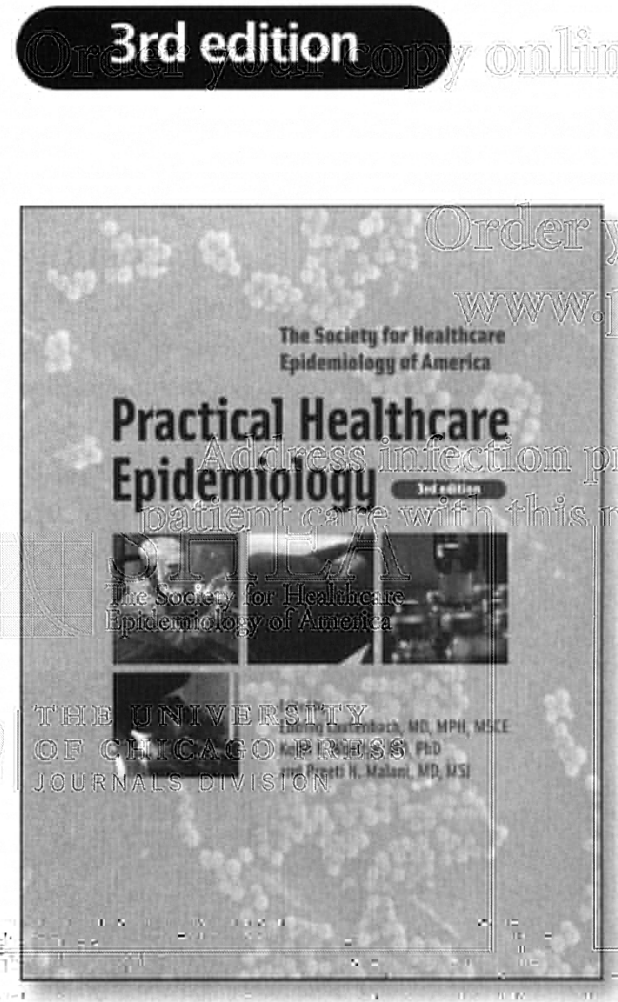

How to:

- Implement and manage surveillance effectively

- Apply epidemiological methods appropriately

- Conduct an outbreak investigation

- Survey for and prevent specific healthcare-associated infections

- Maintain compliance with hand hygiene

-Use patient isolation effectively:

- Control the use of antimicrobials

- Employ the microbiology laboratory and molecular typing systems

- Extend infection control programs to outpatients and long-term care facilities

- Perform exposure workups and manage employee health

- Negotiate with administrators about resources, policy, and pay

- Meet regulatory and accreditation agencies requirements
New chapters on:

- Clostridium difficile infection

- Urinary tract infection

- Healthcare-acquired pneumonia

- Sterilization and dísinfection

- Performance and quality improvement

- Government mandates and infection control

- Preparing for biological disasters and pandemics

- Infection prevention in resource-limited settings

$$
\text { ins: }
$$
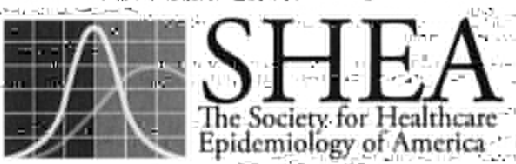
In. C. Baddy, R. John Collier, Toni Darville, Daniel M. Daris, Adrian M.

Gite Tanosian Dunavan, Taul, R. Epstein, Stephen G. Eubanl, Garol Eazell, Thomas
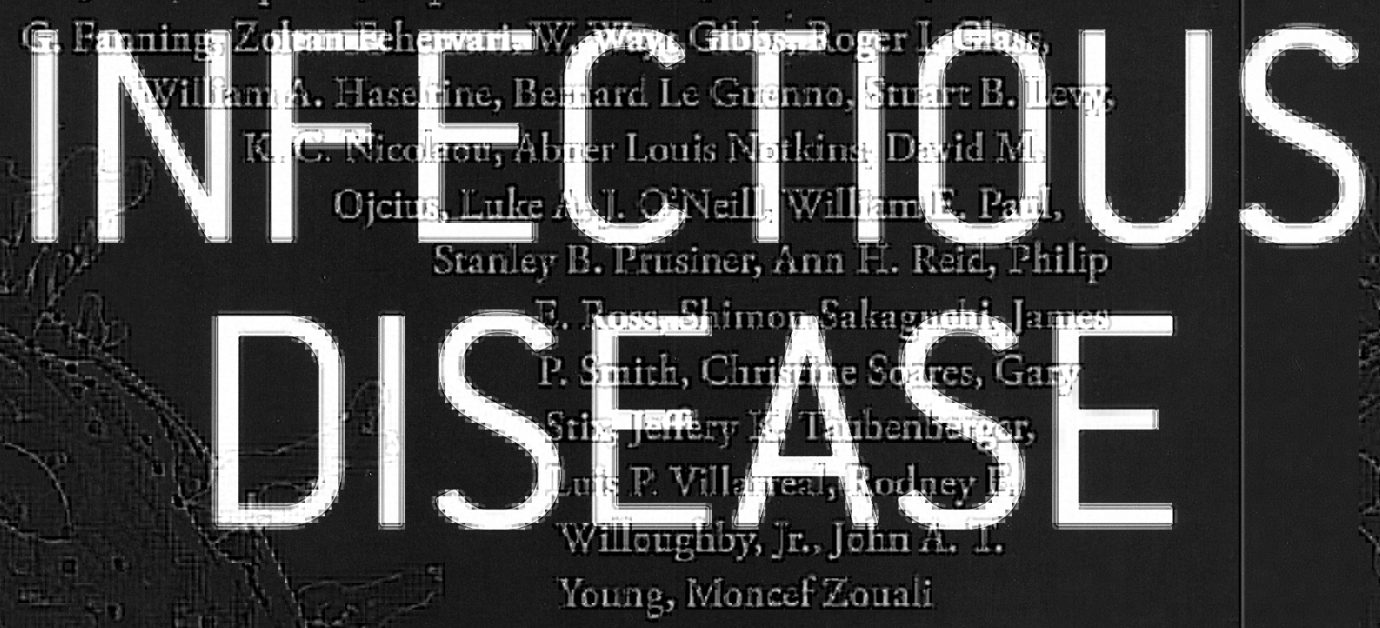

Faper 922.50

\section{- Edited by SCIENTIFIC AMERICAN}

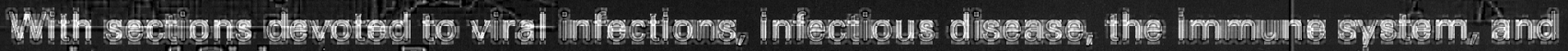

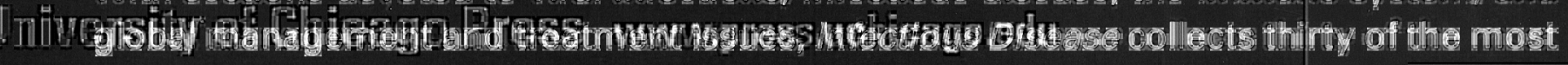

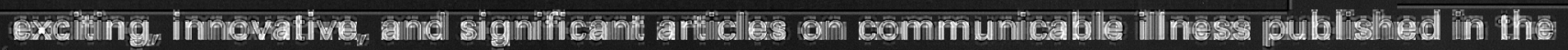

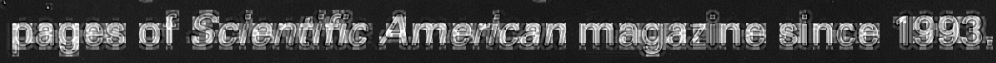

C.

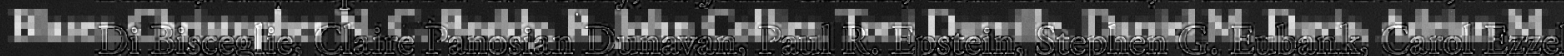

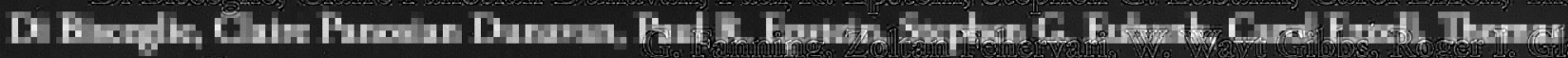

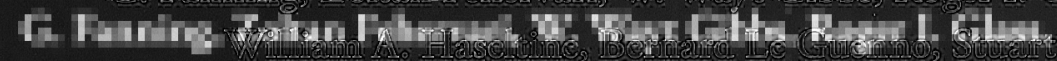

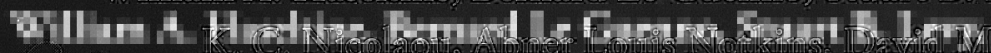

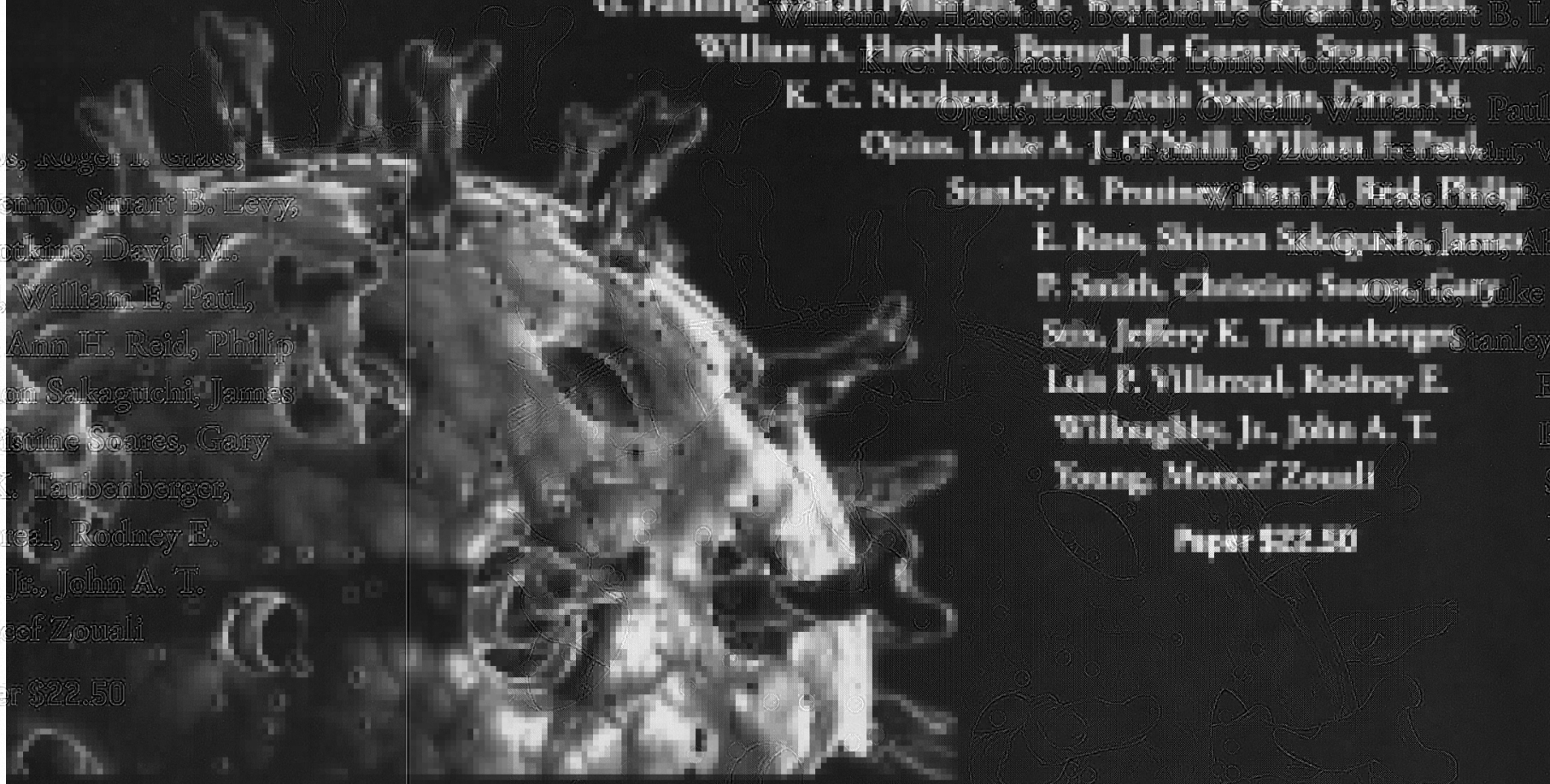


Infection prevention and control in healthcare settings is a critical public health problem rapidly gaining interest.

\section{Are you current with the latest trends and evidence?}

\section{Join SHEA Today!}

Stay on top of emerging science and evidence-based strategies to prevent and control infections and to improve quality-of-care in your healthcare facility.

SHEA supports members' efforts to improve patient care and healthcare worker safety through:

- Research

- Education \& Training

- Policy Development

- Evidence-based Practical Guidelines

- Mentorship and Professional Development

\section{Application Details www.shea-online.org info@shea-online.org (703) 684-1006}

Annual membership offers:

- Subscription and online access to Infection Control and Hospital Epidemiology (ICHE), the official journal of SHEA

- Epidemiology News and e-newsletter

- Discounted registration on SHEA educational programming

- Online member network and job board
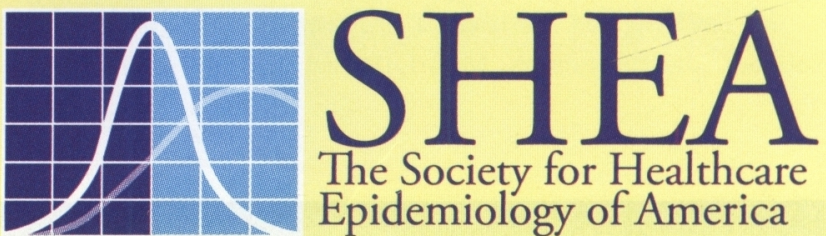

The Society for Healthcare Epidemiology of America 


\section{Tegaderm '" CHG}

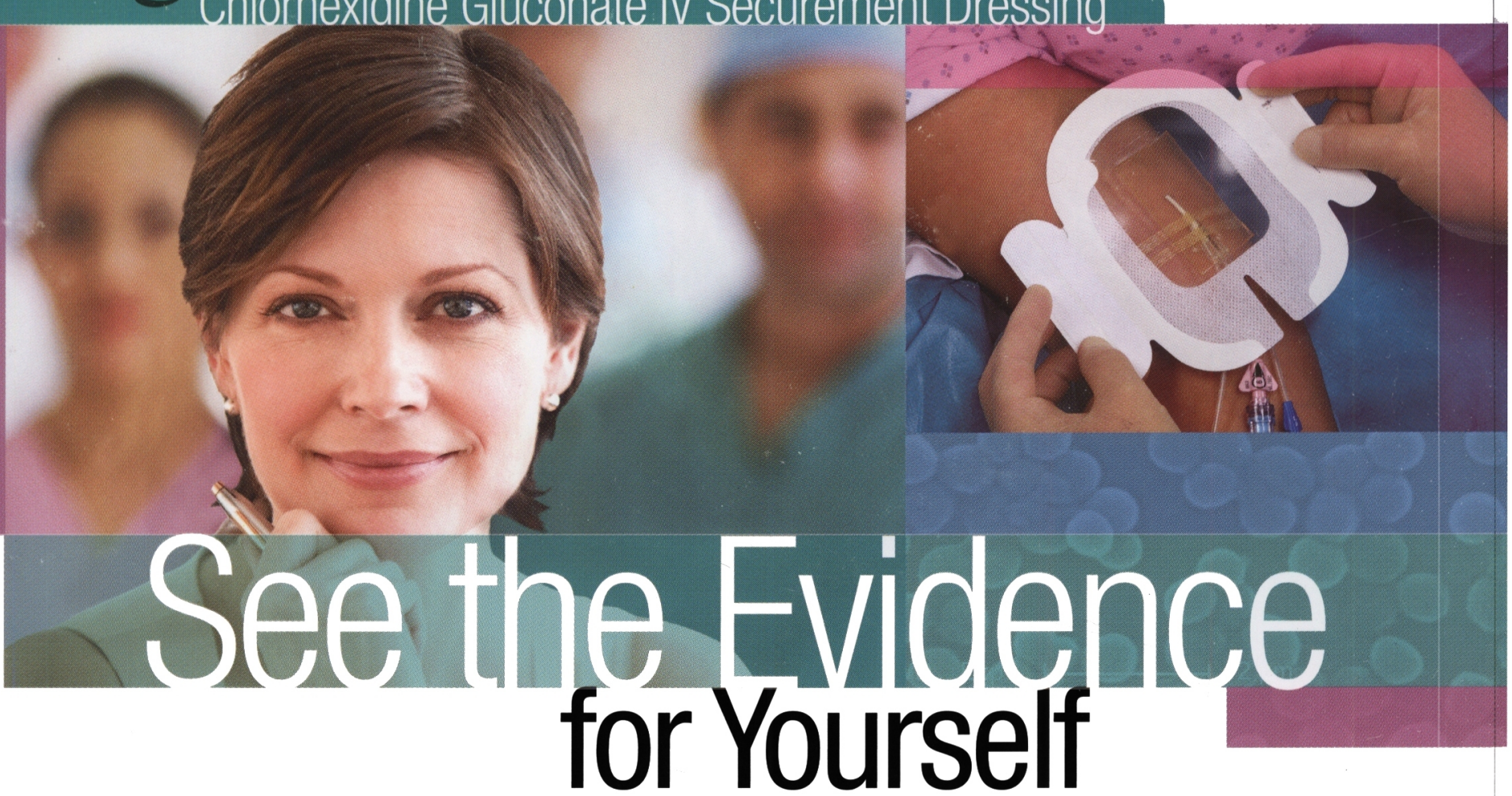

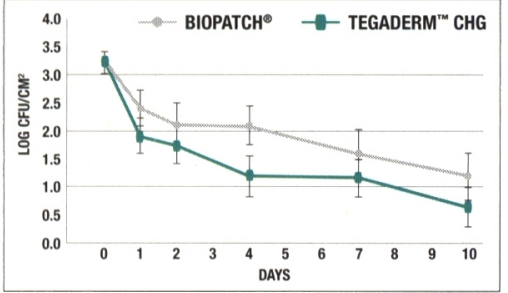

Proven more effective than BioPatchº at reducing skin flora on healthy volunteers for up to 10 days.

\section{The only transparent IV site dressing integrated with a CHG gel pad proven to reduce skin flora better than BioPatch:.}

You know reducing skin flora at the catheter insertion site helps to reduce or prevent CRBSIs. The CDC recommends transparent dressings and the use of $\mathrm{CHG}$ to reduce skin flora at the IV site. In studies, 3M"' Tegaderm"' CHG was proven to be:

- As effective as, or better than BioPatch ${ }^{\circ}$, at reducing skin flora on healthy volunteers for up to 10 days'

- More effective than BioPatch at preventing re-growth of skin flora on healthy volunteers at 7 days'

- Statistically better than BioPatch in overall performance, ease of applying correctly, and ability to the see IV site - as rated by 12 out of 12 clinicians ${ }^{2}$

Tegaderm " $\mathrm{CHG}$ is the only transparent IV site dressing integrated with a $\mathrm{CHG}$ gel pad proven to reduce skin flora, a leading cause of CRBSIs.*

Visit www.3M.com/tegadermchg4 to see the evidence for yourself. 